\title{
BMJ Open Which strategy for using medical and community masks? A prospective analysis of their environmental impact
}

\author{
Alexandre Bouchet, ${ }^{1}$ Julien Boucher, ${ }^{1,2}$ Kevin Schutzbach, ${ }^{3}$ Nicolas Senn (i) , ${ }^{3}$ \\ Blaise Genton, ${ }^{3}$ David Vernez (10 ${ }^{3}$
}

To cite: Bouchet A, Boucher J, Schutzbach $\mathrm{K}$, et al. Which strategy for using medical and community masks? A prospective analysis of their environmental impact. BMJ Open 2021;11:e049690. doi:10.1136/ bmjopen-2021-049690

- Prepublication history and additional supplemental materia for this paper are available online. To view these files, please visit the journal online (http://dx.doi.org/10.1136/ bmjopen-2021-049690).

Received 29 January 2021 Accepted 16 August 2021

Check for updates

(C) Author(s) (or their employer(s)) 2021. Re-use permitted under CC BY-NC. No commercial re-use. See rights and permissions. Published by BMJ.

${ }^{1} \mathrm{EA}$ - Environmental Action, Research Consultancy, Lausanne, Switzerland ${ }^{2}$ University of Applied Sciences and Arts Western Switzerland, Yverdon-les-Bains, Switzerland ${ }^{3}$ Center for Primary Care and Public Health (Unisanté), University of Lausanne, Lausanne, Switzerland

Correspondence to Professor David Vernez; david.vernez@unisante.ch

\section{ABSTRACT}

Introduction The use of personal protective equipment, especially medical masks, increased dramatically during the COVID-19 crisis. Medical masks are made of synthetic materials, mainly polypropylene, and a majority of them are produced in China and imported to the European market. The urgency of the need has so far prevailed over environmental considerations.

Objective Assess the environmental impact of different strategies for the use of face mask.

Method A prospective analysis was conducted to assess the environmental impact of different strategies for the use of medical and community masks. Eight scenarios, differentiating the typologies of masks and the modes of reuse are compared using three environmental impact indicators: the Global Warming Potential (GWP100), the ecological scarcity (UBP method, from German 'Umweltbelastungpunkte') and the plastic leakage (PL). This study attempts to provide clear recommendations that consider both the environmental impact and the protective effectiveness of face masks used in the community.

Results The environmental impact of single-use masks is the most unfavourable, with a GWP of $0.4-1.3 \mathrm{~kg} \mathrm{CO}$ eq., depending on the transport scenario, and a PL of $1.8 \mathrm{~g}$, for a 1 month protection against COVID-19. The use of homemade cotton masks and prolonged use of medical masks through wait-and-reuse are the scenarios with the lowest impact.

Conclusion The use of medical masks with a wait and reuse strategy seems to be the most appropriate when considering both environmental impact and effectiveness. Our results also highlight the need to develop procedures and the legal/operational framework to extend the use of protective equipment during a pandemic.

\section{INTRODUCTION}

The decrease in industrial activity during the COVID-19 confinement and the decline in intranational and international mobility has led to a significant drop in $\mathrm{CO}_{2}$ emissions. An average decrease of $6.4 \%$ in yearly $\mathrm{CO}_{0}$ emissions was observed worldwide for $2020 .^{2}$ Positive effects have also been observed on other air pollutants, such as Particulate matter (PM), Nitrogen oxides (NOx), Sulfur dioxides $\left(\mathrm{SO}_{2}\right)$ and on river pollution. ${ }^{3}$ However, some observations made in China, near

\section{Strengths and limitations of this study}

- This study provides an environmental assessment based on three indicators (GWP 100, UBP and plastic leakage) for different mask type and use strategies.

- Eight mask use and reuse strategies were considered.

- The assumptions used in the life cycle assessment (transport, end of life and littering) are based on the European context and do not necessarily apply to other regions.

- The weight and composition of the masks used in this study are those of typical, commercially available masks but do not represent the variability from one manufacturer to another.

Hubei's epicentre, show an unclear environmental picture, with a lower decrease in air pollutants than expected. ${ }^{4}$ Due to the temporary nature of the confinement measures, some authors argue that the longer term effects of the COVID-19 crisis on the environmental footprint of human activities remain highly uncertain and may offset the observed short-term environmental benefits. ${ }^{5}$ In the USA, a sharp drop in jet fuel and gasoline consumption has been observed during the crisis, leading to a decrease in $\mathrm{CO}_{2}$ emissions of around $15 \%$. However, it has been estimated that in a scenario of sustainable impact on the economy, the consequences of delayed investment in green energy and traffic-related emission reduction programmes alone could outweigh the short-term effects. ${ }^{6}$ The evolution of some activities or consumption patterns during the COVID-19 crisis are also likely to worsen the environmental balance: development of e-commerce (increase of transport distances and packaging), high consumption of disinfection products and massive COVID-19 screening in populations (increase in medical consumables).

The consumption of protective equipment and most particularly face masks has 
also experienced a sharp increase during the crisis. ${ }^{78}$ To meet the growing demand, the production of disposable masks has dramatically increased since the first pandemic wave. ${ }^{9}$ By June 2020, China was producing 200 million face masks per day, 20 times more than in February of the same year. ${ }^{10}$ With the second pandemic wave, the wearing of face masks was mandatory in closed spaces and densely populated areas in many countries. Medical masks and community masks have become essential tools in the fight against the spread of the virus.

Given the extensive use of facemasks, there is an urgent need to take into account the environmental impact of this practice and ways to extend the life of this equipment. Several arguments can be put forward: (1) the bulk of production comes from Asia, ${ }^{11}$ resulting in significant use of transportation to supply regions such as Europe and the USA, (2) medical masks are intended for single use, resulting in additional waste and possible littering of used masks and (3) medical masks and some community masks are made of plastic. Poor management of this waste can therefore contribute to the presence of macroplastics and microplastics in the environment, particularly in the ocean. ${ }^{12}$ Considering that $3 \%$ of masks could enter the environment (overall loss rate), it is estimated that up to 1.56 billions disposable masks could have entered the ocean in 2020, which represents between 4680 and 6240 tons of plastic pollution to the marine environment. ${ }^{13}$ Life cycle assessment (LCA) conducted on face masks in UK also shows that the environmental impact of disposable masks are generally higher than recycled masks. In the absence of recycling, the production of waste in this country, as a consequence of the use of one mask each day for a year by the entire British population, was estimated at 124000 tons, including 66000 tons of non-recyclable contaminated plastic. ${ }^{14}$ Many countries are attempting to restrict the use of single-use plastics, including restricting the use of plastic bags. The increase in plastic waste is putting pressure on the waste management system to find new strategies to deal with this change ${ }^{15}$ However, there is good evidence that face masks used in the community provide protection against COVID-19 infections, ${ }^{16}$ even though effectiveness can be very different according to the type of masks, the wearing adherence or the environmental parameters (eg, humidity and heat).

In this study, we aim to explore and compare the environmental impact of the different masks used in the community and attempt to provide clear recommendations on the best compromise between protection effectiveness and environmental impact.

\section{METHOD}

The environmental impact assessment proposed in this study is based on: (1) the construction of scenarios of mask use in the general population, distinguishing their typology and modalities of reuse and (2) the analysis of these scenarios using three impact indicators, reflecting global warming, plastic littering and ecological scarcity (UBP method, from German 'Umweltbelastungpunkte').

\section{Mask typology}

Three types of masks, intended for general public use, were considered: medical masks, community masks and labelled community masks. Filtering facepiece respirators, such as N95 (USA) and FFP2 (EU), which are mainly used by healthcare professionals, are not considered in this study.

Medical masks (or surgical masks) are originally intended for single use and designed to protect patients from possible pathogens exhaled by the medical personnel. In the context of the COVID-19 pandemic, these masks have been widely used outside of healthcare settings to protect the public by preventing pathogens from leaving the wearer and thus from being transmitted to others in the vicinity of the wearer. In Europe, medical masks must meet the requirements of EN 14683 and must comply with the Medical Devices Directive (EU) 2017/745. Medical masks are usually constituted of three different layers of non-woven fabric, generally in polypropylene (referred here further as PP masks). ${ }^{17} \mathrm{~A}$ majority of them are produced in China and imported by ship in large quantities on the European market. However, during the first pandemic wave in spring 2020, due to the lack of filtering facepiece respirators and medical masks, emergency shipments were made by air.

The term community mask encompasses all nonprofessional masks that are intended to protect the general public from infection, essentially in reducing the emissions from the wearer (source control). Community masks range from homemade cotton masks (referred here further as COT masks) to more or less sophisticated textile masks. Community masks have the advantage that they can be produced locally, either centrally in the case of commercial masks or at home for personal use. The performance of community masks is not subject to legal requirements, so their quality can vary greatly. In some countries, quality labels have been proposed, allowing minimum performance requirements to be defined on a voluntary basis. This is the case, for instance, of the French AFNOR label and of the Swiss TESTEX label (referred here further as PES masks). Currently, labelled masks represent only a minority of production, probably due to higher manufacturing costs. While 'common' community masks are generally made of cotton or other textiles of natural origin, labelled masks, which require greater technicality, are made of polymers, such as elastane or polyester. Community trade masks without labels were considered to come from the wider European market. For the labelled masks, the origin is more specific, since the AFNOR and TESTEX labelled masks are, to our knowledge, only produced in France and Switzerland, respectively. 


\section{Reuse strategy}

The lack of protective means and the need to extend the life cycle of masks during the first COVID-19 wave generated numerous studies on their reuse. Although medical masks are normally intended for single use, it has been shown that certain physical treatments such as Ultraviolet-C (UVC), microwaves or dry heat can effectively decontaminate them without significantly altering their barrier capacity. The latter method is of particular interest for the treatment of medical masks, as it is accessible in all households. It has been shown exposure to at least $70^{\circ} \mathrm{C}$ for $30 \mathrm{~min}$ is sufficient to effectively decontaminate surgical masks or respirators. ${ }^{18-20}$

Another alternative, which has yet to be validated, is the wait and reuse strategy. The viability of the virus deposited on a surface decreases significantly after a few hours. Tests on surgical masks have shown that under ambient temperature and humidity conditions $\left(22^{\circ} \mathrm{C}\right.$, $65 \%$ Relative Humidity), a 3-log reduction in virus load was achieved after $4-7$ days. ${ }^{21}$ In a similar way to what has been proposed by the N95Decon scientific group for respirators, surgical masks could therefore be stored at room temperature for 7 days before being reused (by the same user).

The situation with community masks is more straightforward since they are designed with the intent of cleaning and reusing by the general public. The issue of maintaining performance is also less critical since there are no legal requirements for this type of mask. The strategy considered here is therefore that of a reuse after a decontamination at home in a washing machine at $60^{\circ} \mathrm{C}$. Labelled community masks are a special situation, since maintaining their performances is conditioned by the limitation of the number of washing cycles, to 20 and 5 washes for the AFNOR and TESTEX labels, respectively. ${ }^{22} 23$

\section{Environmental impact assessment}

This study follows the methodology of LCA and considers all the life cycle stages of the different masks including production, transport, use (decontamination) and end

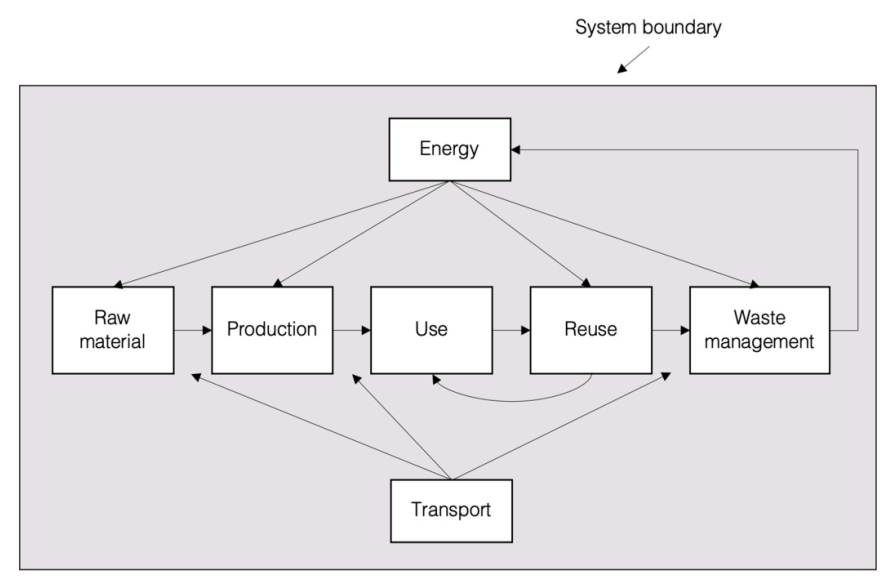

Figure 1 Illustration of the system boundary for all scenarios involved in the study. of life (see figure 1). The primary data sources used and hypothesis are referenced throughout this article. The secondary data used to perform the LCA analysis are based on the Ecoinvent database (https://www.ecoinvent.org/ database/database.html). A proprietary Excel tool developed by the authors was used to perform the LCA based on Ecoinvent datasets. Unless otherwise mentioned, the functional unit (FU) chosen for the comparison of the masks is 'to equip one person with a mask during a month'. Several environmental impact indicators were considered:

- The Global Warming Potential (GWP100) index, which expresses the impact of manufacturing, transporting and recycling masks in terms of greenhouse gases. GWP100 expresses the time-integrated warming effect, over a 100-year period, due to the release of a given greenhouse gas in today's atmosphere, relative to that of carbon dioxide (in mass unit kg). ${ }^{24}$

- The UBP method relies on the methodological concept of ecological scarcity and expresses the environmental impact in terms of eco-points. It encompasses for instance the water footprint of cotton production as well as the biodiversity impact of energy production during the use phase. However, calculation using the UBP method has been performed and is available in online supplemental appendix 1 .

- The plastic leakage (PL) expresses the amount of plastic leaving the technosphere and cumulating in the natural environment. PL measures the quantity of plastic ultimately released into the ocean or into the other compartments (freshwater, soils and other terrestrial environments) including both microplastics and macroplastics. ${ }^{25}$ Plastic leakage is a result of both loss and release and can be simply described by the following equation:

\section{Plastic leakage mass $=$ Plastic waste mass $\cdot$ Leakage rate $($ with Leakage rate $=$ Loss rate $\cdot$ Release rate, and}

\section{Loss rate $=$ mismanaged rate + littering rate $)$}

In the case of Switzerland, the only loss occurring is related to littering since the mismanaged rate is equal to $0 \%$. The littering rate will then be assimilated to the leakage rate as we are here assessing the release rate of a low residual value item to all environmental compartments at once, hence equal to $100 \%$. The littering rate used by default for on-the-go plastic is generally ranging between $2 \%^{26}{ }^{27}$ and $12 \% .{ }^{28} \mathrm{~A}$ recent study focusing on masks articulates a littering rate of $3 \%$ worldwide. We used a $2 \%$ littering rate, ${ }^{25}$ yielding a leakage rate of $2 \%$ to all compartments of the environment for the scope of this study.

The destination chosen for masks transport is Switzerland. However, shipping origin and method vary as masks can come from Switzerland, France or China and be transported either by truck, boat or plane. Different assumptions are made for additional environmental burdens during the use phase of the mask life cycle according to 
the decontamination method. For the decontamination in a washing machine, we consider a household washing machine cycle running at $60^{\circ} \mathrm{C}$ during 1 hour 40 min with a dry load of $6 \mathrm{~kg}$ of clothes with an energy use of $1.8 \mathrm{kWh} /$ cycle, a water use of $67.6 \mathrm{~L} /$ cycle and a soap consumption of $65 \mathrm{~g} /$ cycle $^{29}$ We have allocated the energy, water and soap used to wash a mask based on the ratio between the weight of the mask and the total dry load of clothes assumed when running one cycle. These consumptions features have then been scaled up to represent the FU chosen for the study. For the oven sterilisation, we assume that, based on personal measurement, an oven running at $70^{\circ} \mathrm{C}$ during $30 \mathrm{~min}$ consumes $0.345 \mathrm{kWh}$ of electricity. As the oven utilisation is exclusively dedicated to sterilising masks, we had to make an assumption on the number of masks being sterilised at once. We assumed that a batch of five masks were sterilised for each oven utilisation, hence an energy consumption of $0.069 \mathrm{kWh}$ per mask sterilised.

In the end of life stage, we assumed that all masks were incinerated after disposal. Heat and electricity recovery efficiencies in Europe vary quite significantly between different plants, at average values of $31 \%$ for heat and $12 \%$ for electricity. ${ }^{30}$ The strategies for using the masks and the corresponding assessment parameters are summarised in table 1.

\section{Patient and public involvement}

No patient involved.

\section{RESULTS}

\section{Global warming potential}

The $\mathrm{CO}_{2}$-equivalent impact of the different scenarios of mask use is presented in figure 2. The use of disposable masks brought by plane (scenario PP_2), as experienced during the personal protective equipment shortage of the first pandemic wave, is by far the most detrimental with $1.3 \mathrm{~kg} / \mathrm{CO}_{2} \mathrm{eq} / \mathrm{FU}$. Without taking this extreme situation into account, a strong variability is observed between the different scenarios of mask use. There is a factor of 30 between the most unfavourable scenario (PP_1: disposable medical mask brought by boat) and the most favourable scenario (COT_2: home-made washable cotton mask). The differences observed are largely due to the absence of manufacturing impact from the secondhand fabric as well as a very low contribution from the usage phase in scenario COT_2. The decontamination of medical masks by heating (PP_3) is not very advantageous, as well as the use of community masks made of polymers, as long as the number of reuse cycles remains limited. Taking into account the discounted emissions from incineration after disposal leads to a negative contribution of the endof-life stage to the total $\mathrm{CO}_{2}$-equivalent emissions in all scenarios except COT_1 and COT_2. The use of labelled community mask (PES_1 and PES_2) has an intermediate environmental impact, the use of AFNOR masks (French label) being more advantageous than the TESTEX mask (Swiss label). The difference between the two is mainly

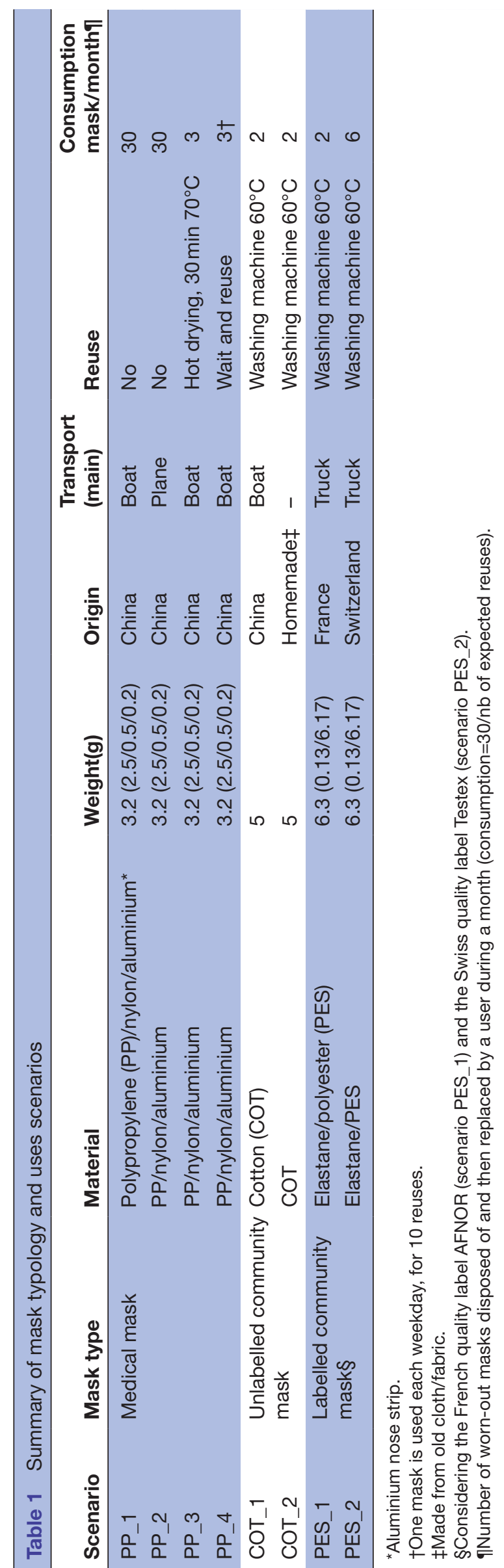




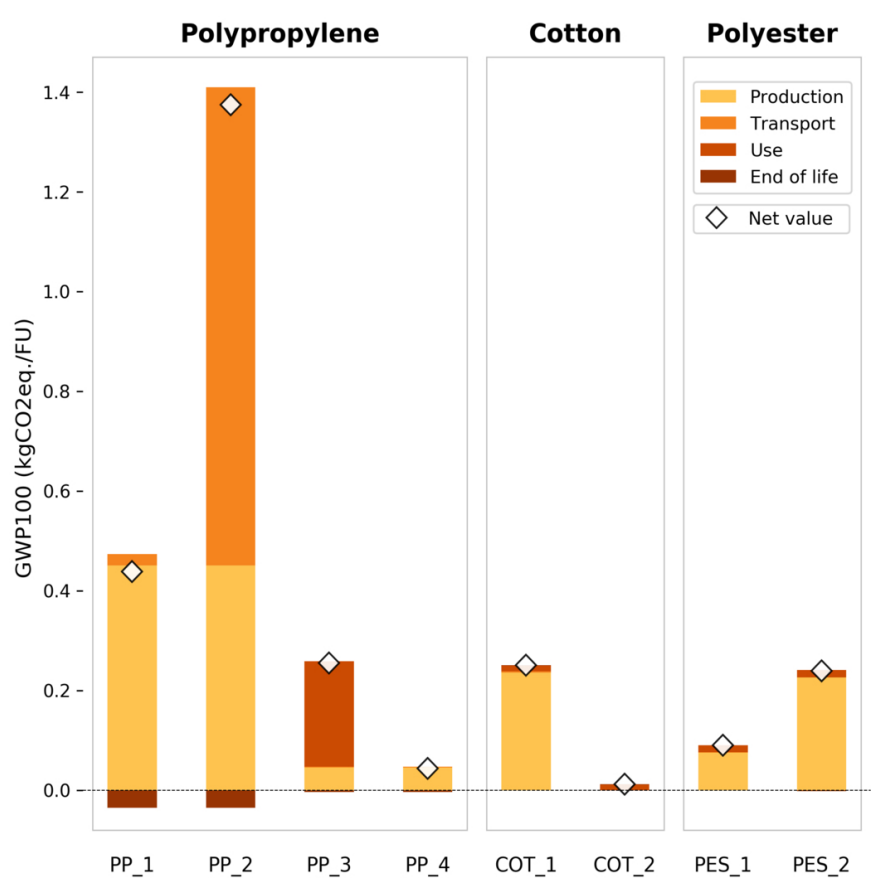

Figure 2 Footprint expressed in GWP100 (kg CO, eq/ FU) for different scenario of mask uses. COT, cotton; FU, functional unit; GWP100, Global Warming Potential; PP, polypropylene.

due to the different number of reuses recommended between the two labels. Overall, the most advantageous scenarios are home-made cotton masks (COT_2) and the extended use of medical masks through a wait and reuse strategy (PP_4).

Results similar to those of the carbon footprint are obtained by considering a broader impact indicator, such as UBP, which integrates water consumption (see online supplemental file 1). The impact related to use increases for all masks when recycled multiple times. The most advantageous scenarios remain however the homemade cotton masks (COT_2) and the extended use of medical masks through a wait and reuse strategy (PP_4). Notably, the impact of decontamination of medical masks by heating ( $\left.\mathrm{PP} \_3\right)$ is more than doubled, making it less advantageous than the single-use scenario of medical masks shipped from China by boat (PP_1).

\section{Plastic leakage}

The impact of the different scenarios of mask use from the point of view of plastic leakage is presented in figure 3. Unsurprisingly, cotton masks do not generate plastic leakage. Disposable medical masks have a high PL of $1.8 \mathrm{~g} / \mathrm{FU}$. However, this impact can be reduced by a factor of 10 by reuse procedures, which proportionally reduce production needs.

\section{Number of reuse}

The number of reuses used in the scenarios is based on an estimate of current practices and recommendations. Arguably, this may change depending on usage conditions, material quality or changes in mask labelling

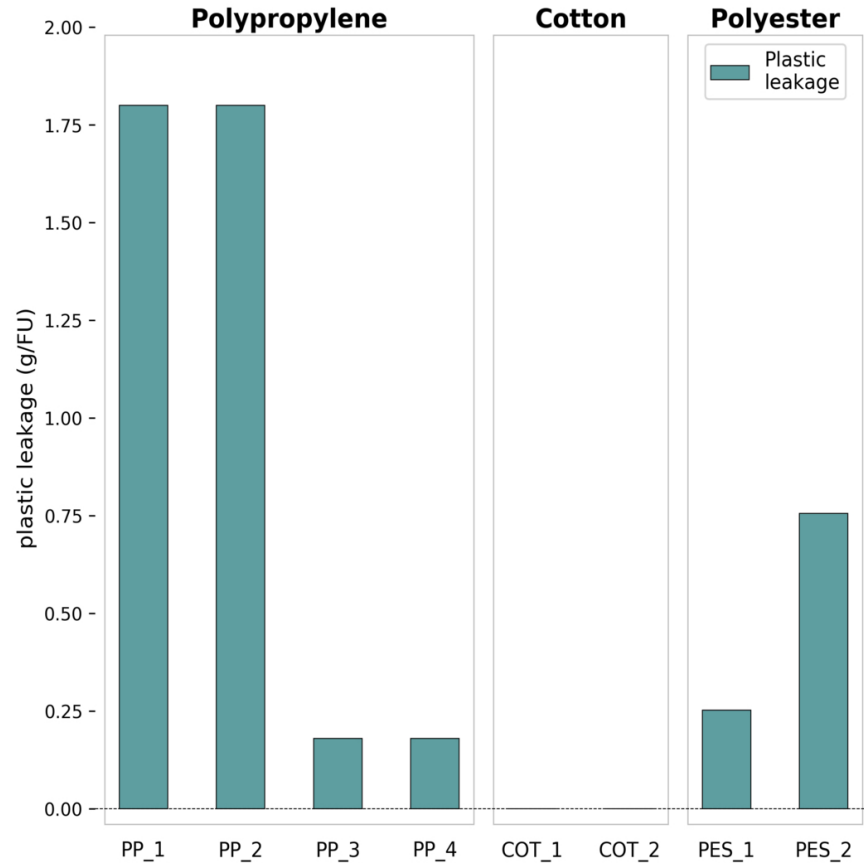

Figure 3 Footprint expressed in plastic leakage (g/FU) for different scenarios of mask uses. COT, cotton; FU, functional unit; PP, polypropylene.

requirements. The effect of the number of reuses on the GWP100 is shown in figure 4. Interestingly, commercial cotton masks (COT_1) reused less than eight times generate more $\mathrm{CO}_{2}$ eq than disposable medical masks shipped by boat (PP_1). Moreover, when used less than 17 times, commercial cotton masks (COT_1) generate more $\mathrm{CO}_{2}$ eq than medical masks decontaminated through dry heating (PP_3). The increase in the number of reuse decreases the gap between the two most advantageous scenarios: home-made cotton masks (COT_2) and the recycling of medical masks through a wait and reuse strategy (PP_4). The curves for scenarios PES_1 and PES_2 are overlapping in figure 4 since the composition of EMPA and AFNOR masks has been assumed identical. The only slight difference between these scenarios, although not significant enough to distinguish both curves on the graph, stems from the distinct origins of the masks.

\section{DISCUSSION}

Consistent with what has been highlighted by other authors, our results show that switching from single-use to reusable masks can significantly reduce plastic leakage and climate change impact. ${ }^{14}$ However, analysis of the different scenarios shows considerable variation between reuse strategies, mainly due to the impact of production and recycling. A footprint reduction (GWP100 or UBP) of $50 \%-90 \%$ can be achieved by switching from a single-use medical mask to a reusable solution. For plastic leakage, this reduction can be from $60 \%$ to $100 \%$. At the population level, these differences are not negligible. We quantified how much $\mathrm{CO}_{2}$ eq impact and plastic leakage 


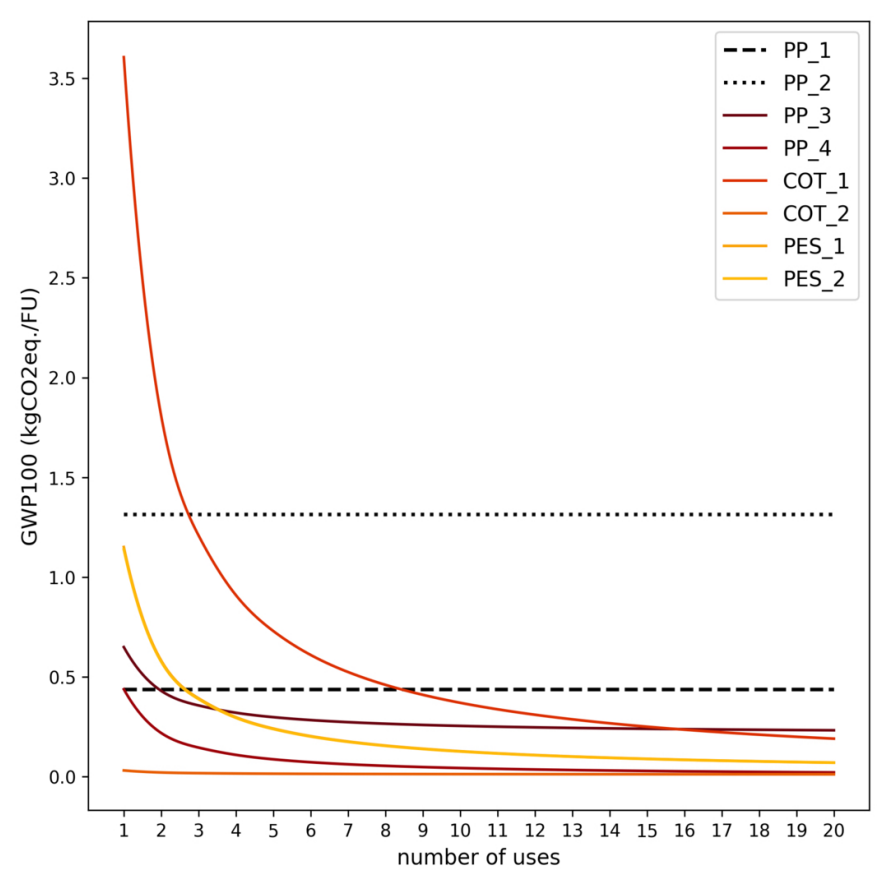

Figure 4 Footprint expressed in GWP100 ( $\mathrm{kg} \mathrm{CO}_{2} \mathrm{eq} /$ FU) for different scenarios as a function of number of uses. COT, cotton; FU, functional unit; GWP100, Global Warming Potential; PP, polypropylene.

would be avoided within a year in Switzerland if $10 \%$ of the entire population was to shift from single-use masks transported by boat (PP_1) to either a wait and reuse strategy for the same masks (PP_4) or home-made cotton masks from old fabric (COT_2). Results are reported in table 2, considering a Swiss population 8606033 in 2019 (source: Federal Statistical Office).

For an impact per passenger transport by aircraft (person/km) of $0.129 \mathrm{~kg} \mathrm{CO}$ eq (source: Reffnet.ch) and an average $1.5 \mathrm{~L}$ plastic bottle weight of $32.6 \mathrm{~g},{ }^{31}$ the uptake of the wait and reuse strategy for the medical masks (PP_4) by $10 \%$ of the population would be equivalent to saving $\mathrm{CO}_{2}$ eq emissions from 5402 individual flights from Paris to New York and preventing 513194 plastic bottles $(1.5 \mathrm{~L})$ from being littered. Similarly, the uptake of home-made cotton masks (COT_2) by the same population share would result in $\mathrm{CO}_{2}$ eq emissions savings analogous to 5830 individual air travels from Paris to New York, and a plastic leakage avoided corresponding to 570 219 plastic bottles $(1.5 \mathrm{~L})$.

Table 2 Environmental impact of a shift from the use of disposable masks to reuse strategies in $10 \%$ of the Swiss population

\begin{tabular}{lll}
\hline & $\begin{array}{l}\mathbf{C O}_{2} \text { eq impact } \\
\text { avoided (t CO }\end{array}$ eq) & $\begin{array}{l}\text { Plastic leakage } \\
\text { avoided (t PL) }\end{array}$ \\
\hline Shifting to PP_4 & 4077 & 17 \\
Shifting to COT_2 & 4400 & 19 \\
\hline
\end{tabular}

COT, cotton; PP, polypropylene.
The environmental impact assessment conducted in this study has several limitations. Data on mask composition, transport and end of life are from the European context. The transposition of these results to other regions, in particular regions with a higher production capacity of medical masks and less reliance on imports, would lead to a modification of the GWP100 and UBP impact. Furthermore, in the absence of precise market distribution data, mask composition and production data were based on typical examples and scenarios rather than statistical data. In practice, there is some variability in manufacturing and shipping arrangements due to different suppliers. From the point of view of the effectiveness of their individual or collective protection, masks are not all equal. The comparison of their performance is not obvious because several parameters influence their effectiveness (droplet penetration, aerosol penetration, fitting to the face, wettability...) ${ }^{16}$ and only medical masks as well as labelled community masks (eg, AFNOR label) have minimum performance requirements for some of these parameters, while a high variability in performance is to be expected among unlabelled community masks. We performed an uncertainty analysis based on low and high values for the littering rate (ranging from $0.2 \%$ to $12 \%$, with the medium value being set at $2 \%$ ). We have observed that the plastic leakage results would be changing proportionally to the leakage rate factor between the medium value and the low or high value but that the climate change or UBP impact results would deviate from the medium case by around $1 \%$ or below. No other uncertainty analysis was undertaken for this study.

The filtration efficiency of the membrane as such has been investigated by several experimental studies. Aydin et al report filtration efficiencies for large droplets in the $100 \mu-1 \mathrm{~mm}$ range of over $98 \%$ for surgical masks and 93\%-98\% for unlabelled community masks of different materials (cotton, polyester and silk). ${ }^{32}$ For finer particles, the performance of unlabelled community masks is however lower. In the $10 \mu$ range $\left(\mathrm{PM}_{10}\right)$, Neupane et $a l^{33}$ show a filtration efficiency of $94 \%$ for surgical masks and $63 \%$ and $84 \%$ for community masks. Systematic reviews of the laboratory results obtained so far suggest that community masks have satisfactory filtration efficiency for large particles $(\mathrm{eg}>5 \mu \mathrm{m})$ but that they have only limited effectiveness against aerosols.

However, the overall performance of the masks is not limited to filtration efficiency alone and will be affected by leaks due to poor fitting to the face, but also by the way the masks are used. Wearing a face mask in a community logic is moreover primarily intended as a collective protection (by reducing the emission of the wearer), rather than an individual protection. This collective effectiveness is difficult to quantify due to the complexity of exposure situations and the presence of other contamination routes (eg, surface contamination). Randomised studies conducted previously on the transmission of viral infections in the community showed that wearing a mask provided some protection in the most adherent individuals ${ }^{34}$ or when 
mask use is accompanied by hand hygiene measures and/ or education on viral infections. ${ }^{35} 36$

The choice of the most appropriate strategy must consider both environmental impact and effectiveness. In terms of mask performance, expectations are generally quite limited from a community protection perspective. To some extent, all masks contribute to community protection by reducing droplet emissions and, to a lesser extent, aerosol emissions from infected wearers. In the absence of minimum performance requirements, this protection is highly uncertain for unlabelled community face masks. Standardised masks, such as medical masks, which offer guarantees in terms of performance and reproducibility, are therefore more advantageous from this point of view. Labelled community masks are also an interesting alternative. Their environmental performance is currently limited by the number of planned cycles of use, which requires frequent replacement. An increase in the number of use cycles covered by the label would reduce significantly their environmental impact. The future use of materials that are less polluting than plastic materials for the manufacture of masks could be an alternative to reduce the environmental cost of their manufacture and plastic leakage. For community masks, this adjustment is relatively simple because many of them are made of cotton and some manufacturers also offer masks made of recycled plastic. For medical masks, a more important effort is necessary, because it requires the complete accreditation of the mask according to EN14683. The scale of the uptake of the reuse strategies suggested in the study by the population will depend on the interest of the government to endorse such practices for community masks and on the efficiency of public awareness campaign. Last but not least, adopting a wait and reuse strategy with medical masks is probably the most economical, which is important in terms of access to protective measures for people with limited financial resources. ${ }^{37}$

\section{CONCLUSION}

The use of medical masks with a wait-and-reuse strategy appears to be the most appropriate, as it is a good compromise between environmental impact and protective efficacy and is accessible in economic terms. Labelled community masks are also an interesting alternative, with an increase in the number of use cycles. Overall, our results highlight the need to develop procedures and the legal/operational framework to extend the use of protective equipment during a pandemic. Such an approach would reduce the environmental impact of the masks and make the public health system more resilient in the event of equipment shortages. They also highlight the need to explore the use of materials that are less polluting than plastics to make the filter material.

Acknowledgements The authors would like to thank Professor J Cornuz from Unisanté, for his advice and ideas in the development of this study.
Contributors JB, NS, BG, KS and DV developed the study concept and design. $\mathrm{KS}$ and $\mathrm{DV}$ conducted the literature review. $\mathrm{AB}$ and JB conducted the impact assessment and data analysis. All authors contributed to the data interpretation. DV wrote the first draft of the manuscript with contributions from JB, AB and NS. All authors contributed to and have approved the final manuscript.

Funding The authors have not declared a specific grant for this research from any funding agency in the public, commercial or not-for-profit sectors.

Competing interests None declared.

Patient consent for publication Not required.

Provenance and peer review Not commissioned; externally peer reviewed.

Data availability statement Data are available upon reasonable request. Raw data were generated at EA-Environmental Action. Derived data supporting the findings of this study are available from the corresponding author DV on request.

Supplemental material This content has been supplied by the author(s). It has not been vetted by BMJ Publishing Group Limited (BMJ) and may not have been peer-reviewed. Any opinions or recommendations discussed are solely those of the author(s) and are not endorsed by BMJ. BMJ disclaims all liability and responsibility arising from any reliance placed on the content. Where the content includes any translated material, BMJ does not warrant the accuracy and reliability of the translations (including but not limited to local regulations, clinical guidelines, terminology, drug names and drug dosages), and is not responsible for any error and/or omissions arising from translation and adaptation or otherwise.

Open access This is an open access article distributed in accordance with the Creative Commons Attribution Non Commercial (CC BY-NC 4.0) license, which permits others to distribute, remix, adapt, build upon this work non-commercially, and license their derivative works on different terms, provided the original work is properly cited, appropriate credit is given, any changes made indicated, and the use is non-commercial. See: http://creativecommons.org/licenses/by-nc/4.0/.

ORCID iDs

Nicolas Senn http://orcid.org/0000-0002-9986-3249

David Vernez http://orcid.org/0000-0002-3304-8727

\section{REFERENCES}

1 Le Quéré C, Jackson RB, Jones MW, et al. Temporary reduction in daily global $\mathrm{CO} 2$ emissions during the COVID-19 forced confinement. Nat Clim Chang 2020;10:647-53.

2 Tollefson J. COVID curbed carbon emissions in 2020 - but not by much. Nature 2021;589:343.

3 Patel PP, Mondal S, Ghosh KG. Some respite for India's dirtiest river? Examining the Yamuna's water quality at Delhi during the COVID-19 lockdown period. Sci Total Environ 2020;744:140851.

4 Almond D, Du X, Zhang S. Did COVID-19 improve air quality near hubei? In: 2020 NBoER, ed. Cambridge, Massachusetts: National Bureau of Economic Research, 2020.

5 Klemeš JJ, Fan YV, Jiang P. The energy and environmental footprints of COVID-19 fighting measures - PPE, disinfection, supply chains. Energy 2020;211:118701-01.

6 Gillingham KT, Knittel CR, Li J, et al. The short-run and longrun effects of Covid-19 on energy and the environment. Joule 2020;4:1337-41.

7 Benson NU, Bassey DE, Palanisami T. COVID pollution: impact of COVID-19 pandemic on global plastic waste footprint. Heliyon 2021;7:e06343.

8 Patrício Silva AL, Prata JC, Walker TR, et al. Increased plastic pollution due to COVID-19 pandemic: challenges and recommendations. Chem Eng J 2021;405:126683.

9 Fadare OO, Okoffo ED. Covid-19 face masks: a potential source of microplastic fibers in the environment. Sci Total Environ 2020;737:140279.

10 Aragaw TA. Surgical face masks as a potential source for microplastic pollution in the COVID-19 scenario. Mar Pollut Bull 2020;159:111517-17.

11 Eurostat. Which country imported the most face masks?: EU Commission, 2021. Available: https://ec.europa.eu/eurostat/web/ products-eurostat-news/-/ddn-20201006-1

12 Shruti VC, Pérez-Guevara F, Elizalde-Martínez I, et al. Reusable masks for COVID-19: a missing piece of the microplastic problem during the global health crisis. Mar Pollut Bull 2020;161:111777.

13 Phelps Bondaroff T, Cooke S. Masks on the beach: the impact of COVID-19 on marine plastic pollution. OceansAsia 2020. 
14 Allison AL, Ambrose-Dempster E, Domenech Aparsi T. The impact and effectiveness of the general public wearing masks to reduce the spread of pandemics in the UK: a multidisciplinary comparison of single-use masks versus reusable face masks. London: UCL Press, 2020.

15 Klemeš JJ, Fan YV, Tan RR, et al. Minimising the present and future plastic waste, energy and environmental footprints related to COVID-19. Renew Sustain Energy Rev 2020;127:109883.

16 Brainard J, Jones NR, Lake IR, et al. Community use of face masks and similar barriers to prevent respiratory illness such as COVID-19: a rapid scoping review. Euro Surveill 2020;25.

17 Chua MH, Cheng W, Goh SS, et al. Face masks in the new COVID-19 normal: materials, testing, and perspectives. Research 2020;2020:1-40.

18 Liao L, Xiao W, Zhao M, et al. Can N95 respirators be reused after disinfection? how many times? ACS Nano 2020;14:6348-56.

19 Pascoe MJ, Robertson A, Crayford A, et al. Dry heat and microwavegenerated steam protocols for the rapid decontamination of respiratory personal protective equipment in response to COVID-19 related shortages. J Hosp Infect 2020;106:10-19.

20 Ou Q, Pei C, Chan Kim S, et al. Evaluation of decontamination methods for commercial and alternative respirator and mask materials - view from filtration aspect. $J$ Aerosol Sci 2020;150:105609-09.

21 Chin A, Chu J, Perera M. Stability of SARS-CoV-2 in different environmental conditions. medRxiv 2020.

22 AFNOR. Masques barrières - Guide d'exigences minimales, de méthodes d'essais, de confection et d'usage. Paris: AFNOR SPEC S76-001 version 1.10, 2020: 45

23 TESTEX. Factsheet - Community Masks Zurich: TESTEX AG, 2020. Available: https://www.testex.com/en/communitymask/

24 IPCC. Climate change. The intergorvernmental panel on climate change, scientific assessment; agriculture, ecosystems \& environment. Cambridge: Cambridge University Press, 1990: 339.

25 Boucher J, Billard G, Simeone E. The marine plastic footprint : towards a science-based metric for measuring marine plastic leakage and increasing the materiality and circularity of plastic. Gland, Switzerland: IUCN, Global Marine and Polar Programme, 2020: 70.
26 Jambeck JR, Geyer R, Wilcox C, et al. Marine pollution. plastic waste inputs from land into the ocean. Science 2015;347:768.

27 Boucher J, Faure F, Pompini O, et al. (micro) plastic fluxes and stocks in lake Geneva Basin. TrAC Trends in Analytical Chemistry 2019;112:66-74.

28 ICF e. Assessment of measures to reduce marine litter from single use plastics. Luxembourg: European Commission, DirectorateGeneral for Environment, 2018.

29 Bourrier C. Washing machine - ETH sustainability summer school 2011 [Web archive]. Zurich: ETH, 2011. http://webarchiv.ethz.ch/ sustainability-v2/lehre/Sommerakademien/so2011/washies_report. pdf

30 Reimann D. CEWEP energy report III: results of specific data for energy, R1 plant efficiency factor and NCV of 314 European Wasteto-Energy (WtE) plants. Bamberg, Germany: CEWEP, Confederation of European Waste-to-Energy Plants, 2012.

31 Islam MS, Uddin MJ, Alshehri K. Plastic waste and carbon footprint generation due to the consumption of bottled waters in Saudi Arabia. RDMS 2018;5

32 Aydin O, Emon B, Cheng S, et al. Performance of fabrics for homemade masks against the spread of COVID-19 through droplets: a quantitative mechanistic study. Extreme Mech Lett 2020;40:100924.

33 Neupane BB, Mainali S, Sharma A, et al. Optical microscopic study of surface morphology and filtering efficiency of face masks. PeerJ 2019;7:e7142-e42.

34 Maclntyre CR, Cauchemez S, Dwyer DE, et al. Face mask use and control of respiratory virus transmission in households. Emerg Infect Dis 2009;15:233-41.

35 Aiello AE, Perez V, Coulborn RM, et al. Facemasks, hand hygiene, and influenza among young adults: a randomized intervention trial. PLoS One 2012;7:e29744-e44.

36 Larson EL, Ferng Y-hui, Wong-McLoughlin J, et al. Impact of nonpharmaceutical interventions on URIs and influenza in crowded, urban households. Public Health Rep 2010;125:178-91.

37 Siu JY-M. Health inequality experienced by the socially disadvantaged populations during the outbreak of COVID-19 in Hong Kong: an interaction with social inequality. Health Soc Care Community 2020. doi:10.1111/hsc. 13214 